\title{
The Inequality-Trust Nexus Revisited: At What Level of Aggregation Does Income Inequality Matter for Social Trust?
}

\section{Georg Kanitsar ${ }^{1}$ (D)}

Accepted: 3 February 2022 / Published online: 18 February 2022

(c) The Author(s) 2022

\begin{abstract}
The negative linkage between income inequality and social trust is widely acknowledged. Despite this consensus, it remains unclear at what level of aggregation income inequality matters most to the cultivation of social trust. In a comprehensive review, Wilkinson and Pickett (Annu Rev Sociol 35:493-511, 2009) speculate that income inequality is most important when measured at the societal level, whereas for lower units of aggregation economic development becomes a stronger predictor. Merging regional inequality data for 216 regions in 22 European countries (2010-2014) to the European Social Survey, this paper is the first to examine this claim for social trust. The results demonstrate that in nonEastern European countries most of the variation in social trust is accounted for by differences in inequality between countries rather than differences in inequality within countries. For economic development, the opposite is true. Within-country differences in economic development relate significantly to social trust, while between-country differences do not. I conclude that social trust is more strongly affected by the stratification of society as a whole than by income inequalities within smaller units of aggregation.
\end{abstract}

Keywords Income inequality $\cdot$ Social trust $\cdot$ European regions $\cdot$ Social fractionalization · Status competition $\cdot$ Multilevel modelling

\section{Introduction}

Social trust promotes a vibrant civic culture, facilitates spontaneous cooperation, supports economic markets, and weaves the separate parts of society into a cohesive whole (Cook, 2005; Durkheim, 1933; Granovetter, 1985). However, social trust is at risk as economic inequality divides and disintegrates societies. In recent years, a mounting number of empirical studies have pointed to a negative relationship between income inequality and social trust (Fairbrother \& Martin, 2013; Hastings, 2018; Larsen, 2013; Rothstein \& Uslaner, 2005; Uslaner, 2002; Uslaner \& Brown, 2005). Accordingly, unequal contexts hamper the

Georg Kanitsar

georg.kanitsar@wu.ac.at

1 Institute for Sociology and Social Research, Vienna University of Economic and Business, Vienna, Austria 
formation of trust, as they lead to social fractionalization and status competition (Bjørnskov, 2008; Wilkinson \& Pickett, 2009). Despite this consensus, it remains unclear at what level of aggregation income inequality and its underlying mechanisms are most relevant to the cultivation of social trust.

In a comprehensive review, Wilkinson and Pickett (2009) speculate that inequality is most important when measured at the societal level, whereas for lower units of aggregation economic development becomes a stronger predictor of various health problems and social ills. The authors reason that the effect of inequality is mostly reflected in the stratification system of the society as a whole and depends less on income differences within smaller areas. Until now, however, empirical support for this "size of the area"-claim exists for health outcomes only. It is vital to our understanding of income inequality to determine if this pattern also generalizes to social trust.

This paper is the first to examine the "size of the area"-claim for social trust using a sample of 216 regions in 22 European countries. To this purpose, I merge regional inequality data (2010-2014) from the Luxembourg Income Study and the OECD database of Regional Income Distribution and Poverty to the European Social Survey (2012-2016). Using a multilevel modelling approach with individuals grouped in regions and regions nested in countries, I, first, analyze the impact of income inequality and economic development on social trust across regions as well as across countries and, second, disentangle the effect of the regional predictors into between-country and within-country components.

The study finds robust evidence for a negative association with income inequality and a positive association with economic development at the regional level. More importantly, the findings support the "size of the area"-claim by Wilkinson and Pickett (2009), but only when excluding the Eastern European countries from the analysis. In the non-Eastern countries, income inequality is a more important predictor at the country level than at the regional level. For economic development, the opposite is true. Differences in economic development within a country relate significantly to social trust, while differences between countries do not. In the Eastern countries, there is no association between regional income inequality and social trust. Thus, the study points to another limitation of the inequalitytrust nexus as it suggests that the negative linkage might only hold for economically developed countries with strong democratic institutions.

By analyzing the relative importance of income inequality across the two levels, the study contributes to piecing together the extant evidence on the inequality-trust nexus. Previous work detecting significant relationships has done so predominantly in cross-country comparisons or across US states. By contrast, studies focusing on smaller levels of aggregation in single countries did not replicate the relationship (US counties in Fairbrother \& Martin, 2013; Australian neighborhoods in Leigh, 2006a). This paper provides direct evidence that indeed the importance of income inequality for trust decreases at lower contextual units, in our case when moving from countries to regions. At lower aggregation levels, trust is related less to the inequality within the region, but rather to its wealth relative to the rest of society. In tandem, economic development becomes a more crucial predictor of social trust.

The study advances our understanding of the theoretical mechanisms underlying the inequality-trust nexus. Although previous efforts have robustly documented the relevance of social fractionalization and status competition in the context of inequality (Delhey \& Dragolov, 2014; Hastings, 2018; Layte \& Whelan, 2014; Paskov, 2016; Paskov et al., 2017), it is usually unspecified to what level of aggregation these mechanisms apply. The present findings suggest that social fractionalization might be more strongly reflected in the class divisions of society at large than in social mixing within regional clusters. Likewise, 
status competition appears to imply social comparison and sensitivity about social standing at the scale of the overall society, rather than among "neighbors" (Wilkinson \& Pickett, 2009). In that, the findings underline the importance of societal factors-such as welfare states and democratic institutions - that shape social fractionalization and status competition at the country level.

The present study is also among the first to demonstrate that the negative relationship of income inequality and social trust extends to the European subnational level. European regions provide a theoretically meaningful context as many of our interaction experiences, which shape and reproduce social trust, go beyond local contexts such as districts or neighborhoods, but, at the same time, rarely spread over the entire country. In doing so, my work supports the empirical robustness of recent evidence by Charron and Rothstein (2018) using a different dataset and another indicator for inequality. Crucially, however, it goes beyond their analysis by showing that this effect is accounted for mainly by differences in inequality between countries rather than within countries.

\section{Income Inequality and Social Trust: Theories and Hypotheses}

People express trust towards others by believing in their trustworthiness under conditions of unknown outcomes (Robbins, 2016). The renowned generalized trust question captures this belief by asking respondents if they think that "most people can be trusted". Although respondents have different circles of others in mind when they reply to this question, many think about the trustworthiness of anonymous strangers encountered in daily interactions (Delhey et al., 2011). In that, generalized trust differs from particularized trust, which pertains to close-knit communities with high social control (Portes, 1998).

Previous studies have explained individual variations in trust by adverting to personality traits (Delhey \& Newton, 2003), socio-economic success in terms of income or education (Alesina \& La Ferrara, 2002), or ascriptive characteristics like ethnicity and gender (Smith, 2010). In contrast, this paper draws on a growing literature that emphasizes the importance of two contextual factors: income inequality and economic development.

\subsection{The Regional Context}

People cultivate social trust through interaction experiences in their social environment (Hardin, 1993; Van Lange, 2015). Glanville et al. (2013, p. 546) argue that generalized trust is developed in informal social connections with friends, neighbors, and community members. Accordingly, people generalize from their particularized trust in local networks to the trustworthiness of the unfamiliar other (Freitag \& Traunmüller, 2009; Welch et al., 2007). Besides that, interactions with unknown strangers also have a strong bearing on social trust. In these interactions, people learn about the goals and motivations of others and form a belief about the trustworthiness of the people around them (Delhey \& Newton, 2003).

Regions provide a context for interactions in immediate social networks as well as for encounters with unknown strangers. They embed the local contexts, like neighborhoods and districts, in which people make many of their contact experiences with friends or acquaintances. However, other daily activities-commuting to work or school, visiting friends and family, and spending time on leisure activities-regularly exceed these small units of aggregation (Ziller, 2015). That is, our mobility is seldom limited to a single district 
or neighborhood, but spreads over larger geographical areas. Simultaneously, meaningful interactions with unknown others rarely scatter across an entire country. Thus, regions provide a meaningful unit of aggregation for analyzing how contextual factors affect contact experiences and shape generalized trust.

A key factor considered to hamper the build-up of social trust is income inequality. A large number of studies have demonstrated that collectives with uneven distributions of disposable income exhibit lower degrees of social trust (Bjørnskov, 2007; Delhey \& Newton, 2005; Kawachi et al., 1997; Leigh, 2006b; Neckerman \& Torche, 2007).

An oft-quoted mechanism underlying this inequality-trust nexus posits that income inequality leads to social fractionalization and thus increases the social distance of people located at each end of the income distribution (Bjørnskov, 2008). In dispersed contexts, there is less social mixing among people located at different positions in the social ladder. Consequently, individuals will have less contact experiences across the social spectrum and, hence, less opportunities to build-up social trust towards people who are unlike them. Even if social interactions across income groups take place, they are less likely to be fruitful because the lower likelihood of future exchanges reduces incentives for trustworthiness (Hastings, 2018). In a similar vein, it has been argued that social fractionalization amplifies the perceived opposition between the affluent and the less well-off (Fairbrother \& Martin, 2013). The higher the economic distance between the two poles of the income distribution (and the more this economic distance translates into a cultural distance between extravagant lifestyles and relative deprivation), the larger the suspicion and the embitterment at the lower end of the social hierarchy (Gallego, 2016). Anticipating resentment by the poor, the affluent will hesitate to trust them, which potentially reinforces the social divide.

A second theoretical mechanism emphasizes that income inequalities raise the salience of competition. According to Wilkinson and Pickett (2009), unequal contexts make individuals more sensitive about their social standing and raise the importance of status differentiation. Comparisons with others and the anxiety of losing out in status competition lead to stress and are connected to a battery of psychosocial ills. In a nutshell, the authors argue that income inequality increases the importance of status hierarchies and the drive for "self-serving individualism", while it simultaneously undermines social strategies based on reciprocity and cooperation (Wilkinson \& Pickett, 2017). In line, previous work attests that status inferiority is strongly experienced across all income groups when income inequality is high (Delhey \& Dragolov, 2014; Layte \& Whelan, 2014).

Following these arguments, we expect that the higher the regional income inequality, the lower the level of social trust. Past research remains divided on this relationship at the regional level. Charron and Rothstein (2018) find that regions with a higher share of the population being at risk of poverty - a close proxy for income inequality—display less social trust. However, Ziller's analysis (2015, Table 3) reveals no such evidence using the same indicator.

Next to income inequality, the economic development of a region-typically operationalized by the average GDP per capita-is also considered crucial to the formation of generalized trust. The connection between economic development and trust is viewed as a self-reinforcing cycle, as trust helps to overcome the moral hazard problem and facilitates investment, while growth leads to more economic activities in which trust with strangers can be created (Beugelsdijk et al., 2004; Knack \& Zak, 2003; Zak \& Knack, 2001). In wealthier regions, there is less to fear from trust betrayal and less to gain from behaving untrustworthy. Therefore, improved standards of living ease interactions with strangers and provide the necessary conditions for social trust to emerge. In line, Beugelsdijk and Van Schaik (2005) identify a correlation between social capital—an index composed of trust 
and civic participation-and economic development across 54 Western European regions (see also, Tabellini, 2010).

H1 The higher income inequality in a region, the lower is the level of social trust.

H2 The higher economic development in a region, the higher is the level of social trust.

\subsection{The Country Context}

Besides the regional context, trust is also shaped by societal influences at the level of countries. As a case in point, welfare states are mainly organized at this level and contribute decisively to the formation of social trust. For instance, Rothstein and Uslaner (2005) make the case that welfare states create social trust through universal social programs. Universal programs are generally more redistributive and-unlike means-tested programs-do not stigmatize certain socio-economic or ethnic groups (Bjørnskov \& Svendsen, 2013; Kevins, 2019). Hence, universal welfare states nurture a sense of a shared fate, and its citizens are more likely to identify as a moral community (Uslaner \& Brown, 2005). Further evidence indicates that democratic institutions, independent courts, impartial political institutions, and high-quality public services - all of which mainly operate at the level of nation states - are also associated with higher levels of social and political trust (Bjørnskov, 2007; Delhey \& Newton, 2003, p. 99; Giustozzi \& Gangl, 2021).

Against this backdrop, the country level is another important unit of aggregation to determine the association of income inequality and social trust. In this sense, social fractionalization may not just apply to regional contexts, in which it becomes a marker of social mixing and heterogeneity, but also to the society as a whole, in which it reflects the systems of class stratification. As national labor markets define the positions on the social ladder and national welfare states seek to reduce the gap between income groups, people might evaluate the social distance not only to others in their region, but with respect to others in their country. Likewise, status competition might not be confined to social comparisons among those living close together, but could take place within the boundaries of a state.

In fact, most of the extant literature on the associations between social trust and income inequality as well as between social trust and economic development has concentrated on the country level (besides those cited above, see also Olivera, 2015; Stephany, 2017; Whiteley, 2000). Thus, Hypothesis 3 and Hypothesis 4 address well-established claims.

H3 The higher income inequality in a country, the lower is the level of social trust.

H4 The higher economic development in a country, the higher is the level of social trust.

This being said, recent studies suggest that identifying the inequality-trust nexus crucially depends on the selected country set. In particular, Uslaner (2016) claims that the association becomes stronger if Eastern European countries with a post-communist legacy are excluded (see also, Uslaner, 2002). Indeed, the Eastern European countries are said to have experienced low levels of social trust during their communist rule (Paldam \& Svendsen, 2001), as well as in their transition away from Communism (Bjørnskov, 2007; 
Sarracino \& Mikucka, 2017). ${ }^{1}$ Fidrmuc and Gërxhani (2008) show that the gap between the Eastern and the non-Eastern countries can be attributed to differences in economic development and in the quality of formal and informal institutions.

Besides, the Eastern European countries also appear to exhibit a weaker association of income inequality and social trust. Thus, income inequality would affect trust only once a certain level of economic wealth is reached and high-quality institutions are established. Up to this point, economic growth and the installation of democratic institutions appear to be the main antidotes to societal distrust (Barone \& Mocetti, 2016) and play a greater role in alleviating health problems and psychosocial ills (Wilkinson \& Pickett, 2009).

\subsection{The "Size of the Area"-Claim}

Although the importance of income inequality and economic development are well supported by previous research, it remains unclear at what contextual level they matter most for the cultivation of trust. Hastings (2018, p. 82), for instance, recently argued that even if the accumulated evidence on the inequality-trust nexus has evolved to a "stylized fact", "it is not readily apparent what is the appropriate unit of aggregation to measure income inequality" when analysing its effect on trust.

In turn, the implications of income inequality and economic development across different hierarchical levels have been explored more thoroughly for health outcomes. In a review of more than 150 studies, Wilkinson and Pickett (2006) found that inequality matters most when large areas-such as US states or countries-were used as the unit of aggregation, while the evidence turns less supportive for small areas-such as counties and districts (Rostila et al., 2012; Subramanian \& Kawachi, 2004). By contrast, economic development becomes a more powerful predictor in small areas than in large regions. Once the analysis moves to hierarchically lower levels, regions are performing poorly in health outcomes not because of their internal distribution of economic resources, but because they are worse off relatively to the society as a whole.

So far, there is no evidence on whether this "size of the area"-claim generalizes to social trust. However, previous work confirming the negative inequality-trust link has done so mostly in international comparisons, whereas the few studies that have moved to smaller units of aggregation have been unable to identify the negative relationship. Against this backdrop, I expect income inequality to matter more at the level of countries, whereas economic development becomes a stronger predictor for regional units of aggregation. In other words, between-country differences in inequality are more strongly related to social trust than within-country differences in regional inequality. On the other hand, within-country differences in regional economic development matter more to social trust than betweencountry differences in economic development.

H5 Social trust is more strongly associated with income inequality at the country level than at the regional level.

H6 Social trust is more strongly associated with economic development at the regional level than at the country level.

\footnotetext{
${ }^{1}$ Despite consistently showing lower levels of social trust, the Eastern Europe countries are still very heterogeneous (Sarracino and Mikucka, 2017).
} 


\section{Data and Methods}

\subsection{Data}

For the individual level data, I draw on the European Social Survey. The ESS is generally regarded as a high-quality data source with rigorous methodological standards. Most crucially, it provides information about the regions in which respondents reside using the Nomenclature of Territorial Units for Statistics (NUTS) classification scheme. In this study, I merge the ESS dataset with harmonized measures of inequality and income at the country- and regions-level, which I constructed from the Luxembourg Income Study and the OECD database of Regional Income Distribution and Poverty. To merge the datasets, I choose a reference year in the period 2010-2014 for each country, depending on the availability of income inequality data. I then match this data to the next ESS wave following the reference year, allowing for a maximum of a two-year gap between data sources (Table 1). ${ }^{2}$

The NUTS scheme consists of three subdivisions, which differ according to the size of regions. ${ }^{3}$ I grouped respondents to the lowest level of aggregation for which both data on inequality as well as data from the ESS was available. With the exception of Slovenia, which is divided into two regions according to the NUTS-2 scheme, the number of regions per country ranges between 5 and $21 .^{4}$ The median population size of the included regions was 1.4 million, and the mean was 2.7 million. The mean population size of the NUTS1, NUTS-2, and NUTS-3 regions was 5.0, 2.0, and 0.5 million. The average number of respondents per region was 188.7 .

\subsubsection{Social Trust}

Social trust is measured in the ESS by three items. The three items capture responses on a scale from 0 to 10 to the following questions: "Generally speaking, would you say that most people can be trusted, or that you can't be too careful in dealing with people?" (trustworthiness); "Do you think that most people would try to take advantage of you if they got the chance, or would they try to be fair?" (fairness); "Would you say that most of the time people try to be helpful or that they are mostly looking out for themselves?" (helpfulness). I condense the three items into an additive index $(\alpha=0.77)$ and rescale the index to a range from 0 (low trust) to 10 (high trust). Some scholars have expressed concerns about the inclusion of fairness and helpfulness, arguing that they might not tap on generalized trust specifically (Bauer \& Freitag, 2018; Uslaner, 2002). For this reason, I repeat the main analysis for the single trust item in Online Appendix A. In the remainder, I follow the bigger part of the literature (Dinesen, 2011; Reeskens \& Hooghe, 2008), which takes the strong correlation among the three items as indication for a similar latent construct.

\footnotetext{
2 As a robustness check (Online Appendix D), I merged inequality data to wave 6 of the ESS for all countries (except for Austria, which is not included in this wave).

${ }^{3}$ I use the NUTS 2013 classification. None of the changes from NUTS 2010 to NUTS 2013 affect regions for which I use data points outside of the time period in which NUTS 2013 was valid.

4 As Russia is not part of the NUTS nomenclature, I used the 8 Federal districts, the standard administrative division of the statistical agency in Russia, instead.
} 


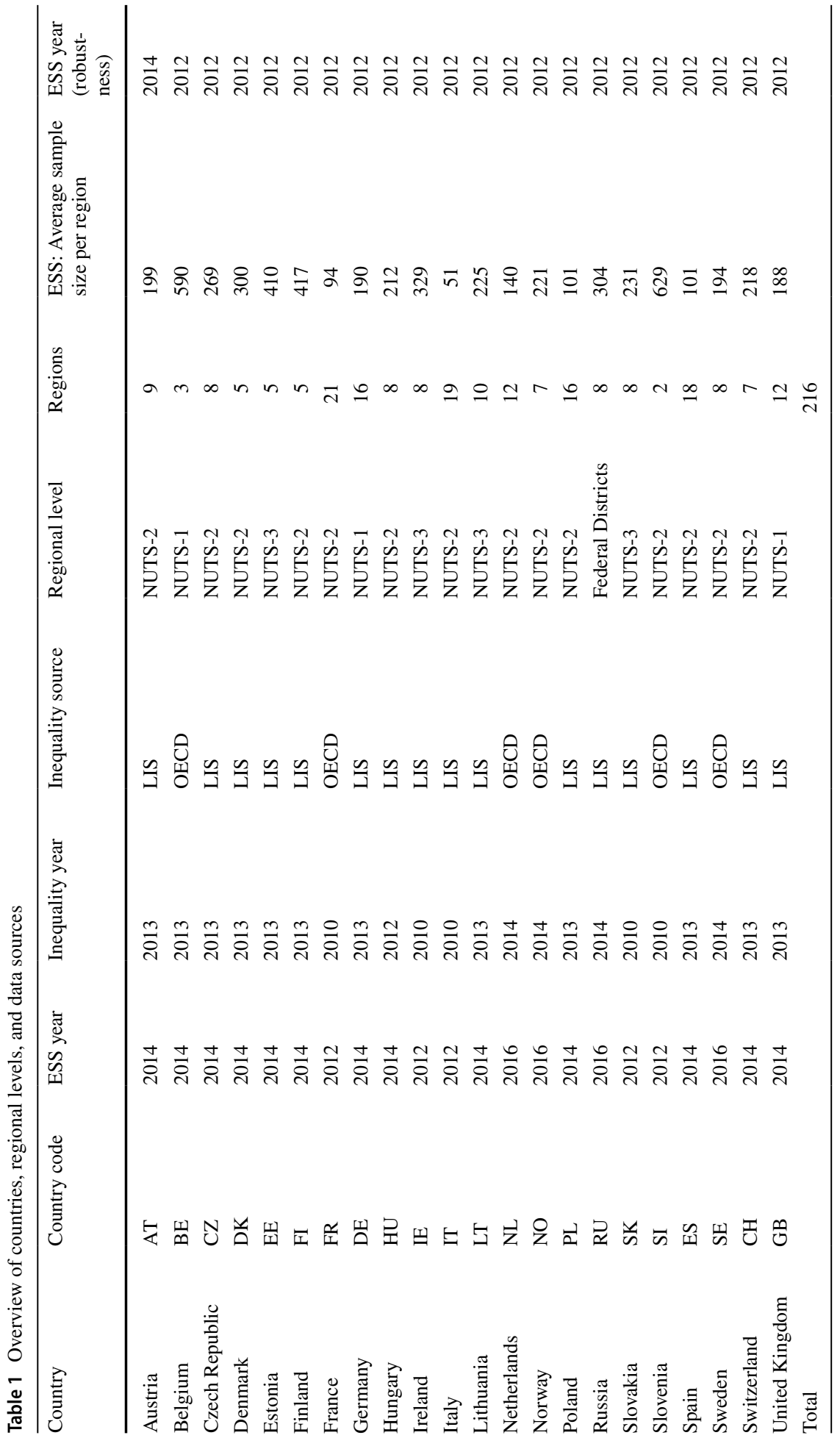




\subsubsection{Contextual Variables: Income Inequality and Economic Development}

The prime data source for the contextual variables is the Luxembourg Income Study (LIS). The LIS acquires and harmonizes data sets from high- and middle-income countries with the objective of facilitating cross-country comparisons. Although the data is not made available on a regular basis for all countries covered and varies with regard to the level of regional disaggregation, LIS offers the most comprehensive and finest-grained source for regional income data. I calculated Gini coefficients and the GDP per Capita based on measures of disposable household income. In LIS, disposable household income is a harmonized variable summarizing household income from labor, capital, pensions, and nonpension public social benefits, net of income taxes and social contributions. The LIS guidelines for creating comparable income variables across waves and countries recommend, first, to recode extreme values at the top and the bottom of the income distribution, second, to correct for the household size by dividing income by the square root of the number of household members (LIS equivalence scale), and third, to weight the data by the household weight [hpopwgt] multiplied by the number of household members [nhhmem] (see also, Savoia, 2019). ${ }^{5}$ I follow these three steps to construct regional and country measures for income inequality (Gini) and economic development (GDP p.C.) and rescale them to a range from 0 to 1 .

Some of the countries in the ESS are either not included in the LIS dataset with respective waves (Belgium, Sweden) or do not use regional clusters matching the ones used in the ESS (France, Netherlands, Norway, Slovenia). To prevent a loss of data points due to missing waves and countries, we add observations from the Regional Income Distribution and Poverty dataset of the OECD to the dataset constructed from LIS. ${ }^{6}$ To assess the fit between the LIS and the OECD data, Online Appendix B identifies a strong correlation $(r=0.9)$ using the data points that are available from both sources. ${ }^{7}$

\subsubsection{Control Variables}

Previous work suggests that trust is related to a number of sociodemographic characteristics and contextual factors (Bjørnskov, 2007; Kevins, 2019). To statistically control for these factors, the analysis includes the following variables at the individual level: gender, age, education (according to 5-level ISCED), income (measured by feelings about household income from 0 "living comfortably on present income" to 3 "very difficult on present income"), marital status ("married","separated or divorced", "widowed", "never married"), employment status ("paid work", "unemployed", "retired", "other"), household size (grouped to "1", "2","3-5" and "more than 5"), religiosity (from 0 "not at all religious" to 10 "very religious"), ethnic minority (dummy variable), foreign born (dummy variable), and victim crime (dummy variable indicating if the respondent or a member of the household had been victim of a burglary or assault in the last five years). In addition, I included as regional-level controls: population density (retrieved from Eurostat), share of

\footnotetext{
${ }^{5}$ Furthermore, I apply LIS Purchasing Power Parity deflators to facilitate comparison across countries (https://www.lisdatacenter.org/resources/ppp-deflators/).

6 Although the OECD dataset comprises less countries and a regional classification on a higher level than LIS, it allows us to add NUTS-1 data for Belgium and Slovenia and NUTS-2 data for France, Netherlands, Sweden, and Norway.

7 All subsequent analyses control for the data source (LIS/ OECD) using a dummy variable.
} 
ethnic minorities (calculated from ESS), and share of foreign-born (calculated from ESS). ${ }^{8}$ Table 3 in the Appendix shows the descriptive statistics for the main variables used in the analysis. After listwise deletion of missing cases, the dataset covers a sample of 38.951 respondents, nested in 216 regions from 22 countries.

\subsection{Estimation Strategy}

To account for the hierarchically nested structure of observations, I apply multilevel modelling (Snijders \& Bosker, 2012). Multilevel modelling accounts for the non-independence of observations in clusters and allows us to disaggregate the effect of upper-level variables in a between (-countries) and a within (-countries, but between-regions) component. In particular, we look at individuals $i$, who are grouped in regions $j$, with regions being nested in countries k. Since, the substantive interest of this study lies in examining the effect of upper-level variables (income inequality and economic development), the multilevel model includes random country-level and region-level intercepts. The model is described by the three formulas:

$$
\begin{aligned}
& y_{i j k}=\beta_{0 j k}+\beta_{1 j k} x_{i j k}+e_{i j k} \\
& \beta_{0 j k}=\gamma_{00 k}+\gamma_{01 k} w_{j k}+u_{0 j k} \\
& \gamma_{00 k}=\delta_{000}+\delta_{001} z_{k}+v_{o o k}
\end{aligned}
$$

The outcome variable trust $y_{i j k}$ is a function of the grand mean $\delta_{000}$, a set of individuallevel control variables $x$, regional-level variables $w$ and country-level variables $z$. The random part of the model corresponds to the region-specific random effects $u_{0 j k} \sim N\left(0, \sigma_{u o}^{2}\right)$, the country-specific random effects $v_{\text {ook }} \sim N\left(0, \sigma_{v o}^{2}\right)$, and the residuals $e_{i j k} \sim N\left(0, \sigma_{e}^{2}\right)$.

I ran three models. All of them include individual-level controls and regional-level controls, and differ only with regard to measures of income inequality and economic development, which are entered at different contextual levels. In Model (1), I test Hypotheses 1 and 2 by including measures of income inequality and economic development at the regional level $\left(w_{j k}\right)$ in the level two specification. In Model (2), I test Hypotheses 3 and 4 by entering grand-mean centered country predictors of income inequality and economic development $\left(z_{k}\right)$ at the third level.

Although Model (1) tests if the inequality-trust linkage extends to European regions, it does not tell us if differences between regions are mainly driven by the differences between countries or the differences of regions within a country. In other words, in Model (1) the effect of the regional predictors can be understood as a weighted average of an effect at level 2 and an effect at level 3. The former (the within effect) captures the difference in income inequality of a region relative to the other regions in a country, while the latter (the between effect) captures the difference between more and less unequal countries (Bell et al., 2018; Enders \& Tofighi, 2007). To disentangle the two effects, Model (3) enters a regional-level predictor centered around the country mean $\left(w_{j k}-\overline{z_{k}}\right)$ and a country-level predictor centered around the grand mean $\left(\overline{z_{k}}-\bar{z}\right)$ for both contextual variables. By centering the regional-level variable on the cluster mean, the model eliminates country-level

${ }^{8}$ Age, religiosity, and the three regional variables are centered at the grand mean. 


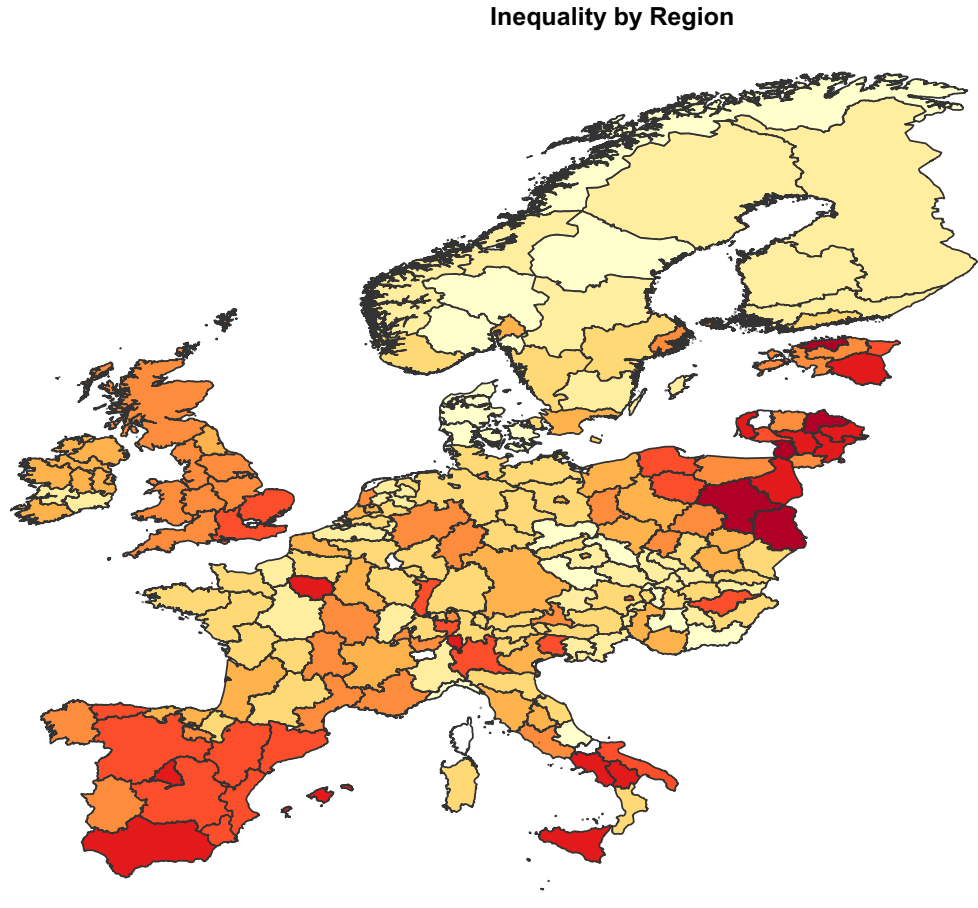

Fig. 1 Inequality by region. Regional Gini coefficients for 216 European regions. The Figure shows the values of the Gini coefficient retrieved from the Luxembourg Income Study and OECD database of Regional Income Distribution and Poverty for the years reported in Table 1

variance and derives a measure for the within-country effect. Likewise, the coefficient on the third level gives us an estimate of how between-country differences in income inequality and economic development affect social trust. ${ }^{9}$ From this, we can infer if the predictors are more strongly associated with social trust on the regional level or on the country level (Hypotheses 5 and 6).

The analysis applies post-stratification weights (based on age, gender, education, and region) at the individual level and inverse probability weights to correct for the fact that countries are represented with different sample sizes.

\footnotetext{
${ }^{9}$ Crucially, this partitioning of the Gini coefficient into a within- and a between-component implies that the latter additionally captures a third residual term, which reflects the overlap of the within-distributions across regions and can also be thought of as an inverse of the stratification of regions (Allanson, 2014; Lambert \& Aronson, 1993).
} 


\section{Results}

\subsection{Descriptive Overview}

Figure 1 provides a first glance at the regional Gini coefficients for the 216 regions in the dataset. ${ }^{10}$ The map confirms established insights about country differences in inequality, as the Scandinavian countries exhibit comparatively lower levels of inequality than the Southern and Eastern European countries. Nevertheless, Fig. 1 also shows a considerable variation of inequality within each country. Specifically, the within-country standard deviation (2.50) of the regional Gini coefficients is only slightly lower than their between-country standard deviation (2.89).

To split up the variation in social trust according to the three hierarchical levels, I calculate Intraclass Correlation Coefficients (ICCs). The ICC of the null model (i.e., an empty model without individual or contextual predictors) calculates how much of the total variance in an outcome variable can be attributed to the variation within clusters and the variation between clusters. In the three-level model, two ICCs can be derived and meaningfully interpreted. The first $I C C_{1}$ determines how much of the total residual variance is made up by the random effects at level 2 (regions) and level 3 (countries). Using the notation $\tau_{0}^{2}=\operatorname{Var}\left(u_{0 j k}\right), \varphi_{0}^{2}=\operatorname{Var}\left(v_{o o k}\right)$, and $\sigma_{e}^{2}=\operatorname{Var}\left(e_{i j k}\right), I C C_{1}$ corresponds to:

$$
I C C_{1}=\frac{\tau_{0}^{2}+\varphi_{0}^{2}}{\tau_{0}^{2}+\varphi_{0}^{2}+\sigma_{e}^{2}}=0.191
$$

$19.1 \%$ of the total variance of social trust can be explained by the groupings of individuals into higher-level units. The second $I C C_{2}$ states how much of this higher-level variation is accounted for by country groupings (level 3 ) relative to region groupings (level 2). Sticking to the notation above, $I C C_{2}$ amounts to:

$$
I C C_{2}=\frac{\varphi_{0}^{2}}{\tau_{0}^{2}+\varphi_{0}^{2}}=0.862
$$

Thus, countries account for $86.2 \%$ and regions for 13.8 (100-86.2) \% of the higher-level variation in social trust. From these numbers, we can infer that most of the between-person variation in social trust is explained by the clustering of individuals into countries. Nevertheless, there are also considerable regional differences in social trust at the subnational level. To visualize the variation in trust across countries and regions, Fig. 2 plots the estimated random effects for each country and Fig. 3 plots the estimated random effects for each region in the six countries with the highest range of random effects.

Figure 2 reproduces the established pattern as many Nordic countries rank relatively high (Delhey \& Newton, 2005) and many Southern and Eastern countries are in the lower third of the graph (Pichler \& Wallace, 2007). Overall, the average trust scores of most countries fall within a 2.5 interval. The range of the regional averages within each country is comparatively smaller, but varies considerably between countries. In some countries (e.g., AT, DK, CZ) there is less than a 0.5 point difference between the average scores of the most and the least trusting region. In other countries (e.g., SK, IT, RU), regions differ

$\overline{10}$ The Russian federal districts are omitted from this representation due to practical reasons. 


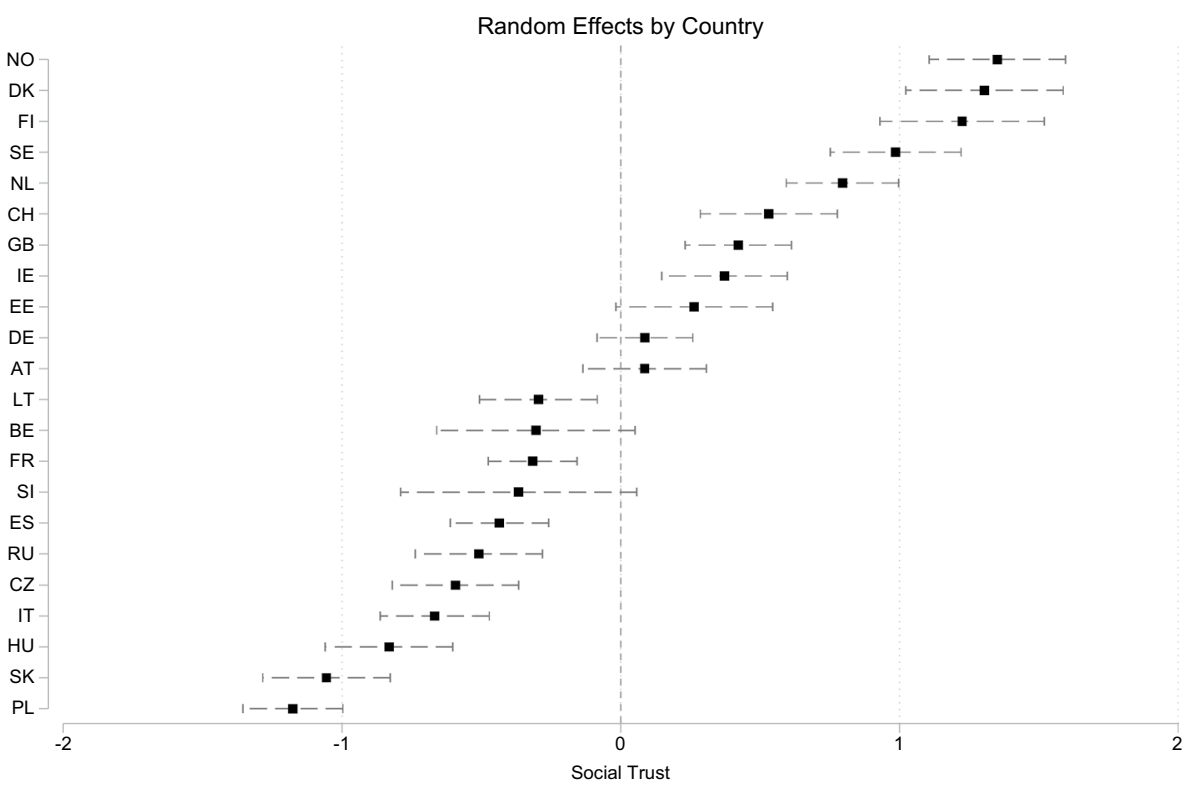

Fig. 2 Random effects by country. Estimated random effects at the country-level (null model). The zero line corresponds to a predicted value of 5.26 for social trust (scaled from [0;10]). Error bars show 95\% CI

more strongly from another, although even the largest distance between regional averages (in RU: 1.34) stays below the spread of the country averages (see also, Charron \& Rothstein, 2018).

Figure 4 presents a first overview of the relationship between income inequality and social trust. The figure plots average trust scores against regional Gini coefficients, distinguishing between Eastern European and non-Eastern European countries. ${ }^{11}$ What is striking is that the relationship between income inequality and social trust is positive in the former country group, whereas it is clearly negative in the non-Eastern countries. Thus, a first visual inspection suggests that the negative inequality-trust nexus does not apply to Eastern European regions. To account for this, the main analysis reports estimates of the contextual variables once across all countries (Models 1a, 2a, and 3a) and once interacted with a dummy variable for Eastern Europe (Models 1b, 2b, and 3b).

\subsection{Main Analysis}

Table 2 presents the results of the main analysis. Models (1a) and (1b) study the effects of income inequality and economic development on social trust at the regional level. Models (2a) and (2b) zoom in on the country level. Models (3a) and (3b) disentangle the withincountry and between-country components of the regional variables. Online Appendix E supplements the full output including the control variables.

$\overline{11}$ The Eastern European countries are CZ, EE, HU, LT, PL, SI, SK, RU. 

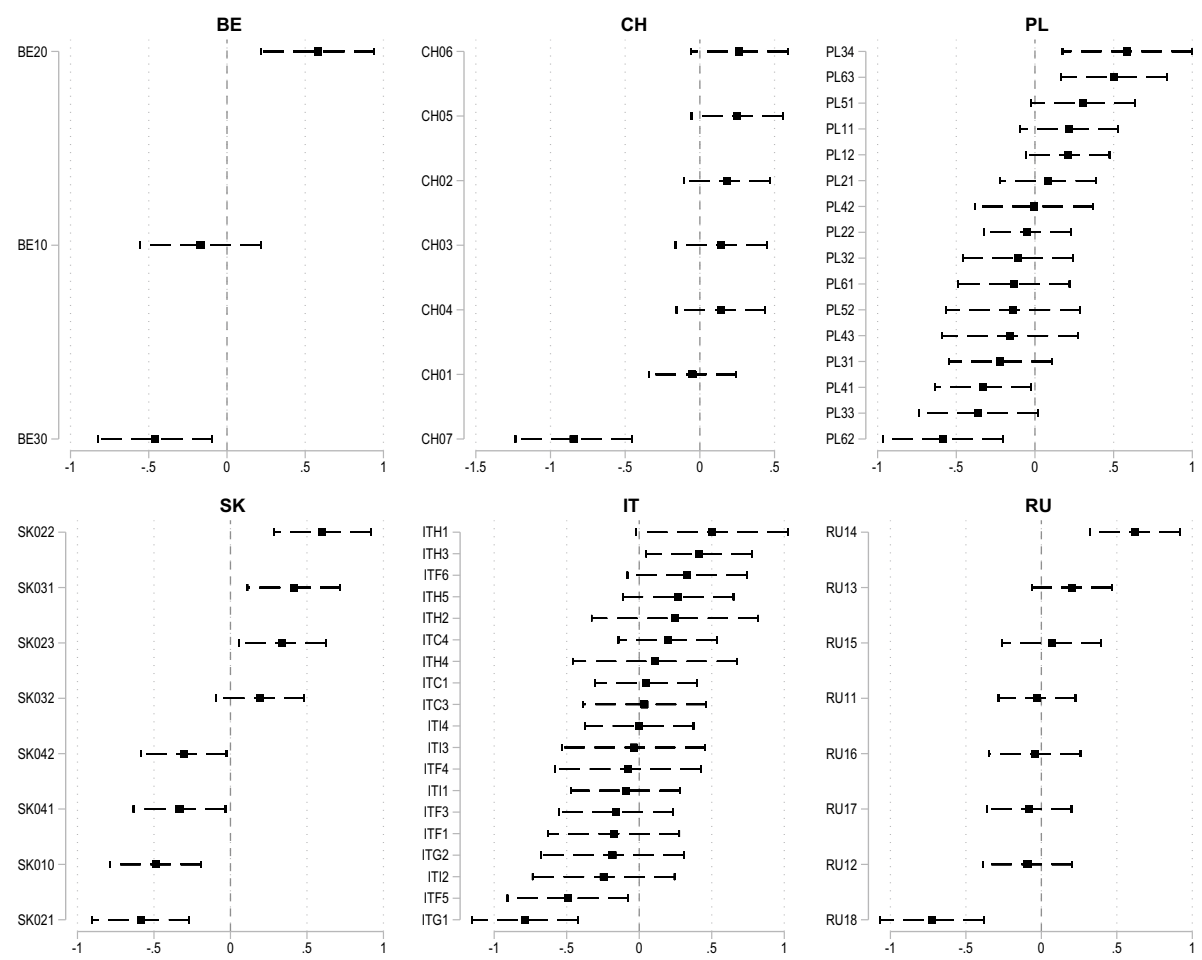

Fig. 3 Random effects by region. Estimated random effects at the regions-level (null model). Error bars show $95 \%$ CI. The figure reports the six countries with the highest range of random effects. Online Appendix $\mathrm{C}$ shows the random effects of all countries. Sorted from left top to right bottom by range of random effects

Across all countries, Model (1a) reveals that social trust is negatively related to income inequality and positively related to economic development at the regional level, providing direct support for Hypothesis 1 and Hypothesis 2. Model (1b) inserts interaction effects for Eastern European countries with Gini region and GDP p.C. region, respectively. In the non-Eastern countries, the effects postulated in Hypothesis 1 and Hypothesis 2 are reproduced. However, both effects are nullified in the Eastern countries. ${ }^{12}$

Models (2a) and (2b) shift the focus to the country level-predictors. Over all countries, specification ( $2 a$ ) shows that the association between inequality and trust is negative but statistically insignificant, whereas economic development is strongly associated with social trust. It is only in Model (2b) that we detect evidence for a negative inequality-trust linkage across the non-Eastern countries. Again, this effect is annihilated in the Eastern country sample. ${ }^{13}$ In turn, when splitting up the sample in Model (2b), the effect of GDP p.C. at the country level vanishes in both country sets.

\footnotetext{
${ }_{12}$ In Model (1b), the effect of Gini region in Eastern Europe is $0.46(\mathrm{p}=0.154)$ and the effect of GDP p.C. region in Eastern Europe is $-0.40(\mathrm{p}=0.727)$.

${ }^{13}$ In Model (2b), the effect of Gini country in Eastern Europe is $0.68(\mathrm{p}=0.346)$ and the effect of GDP p.C. country in Eastern Europe is $1.66(\mathrm{p}=0.540)$.
} 


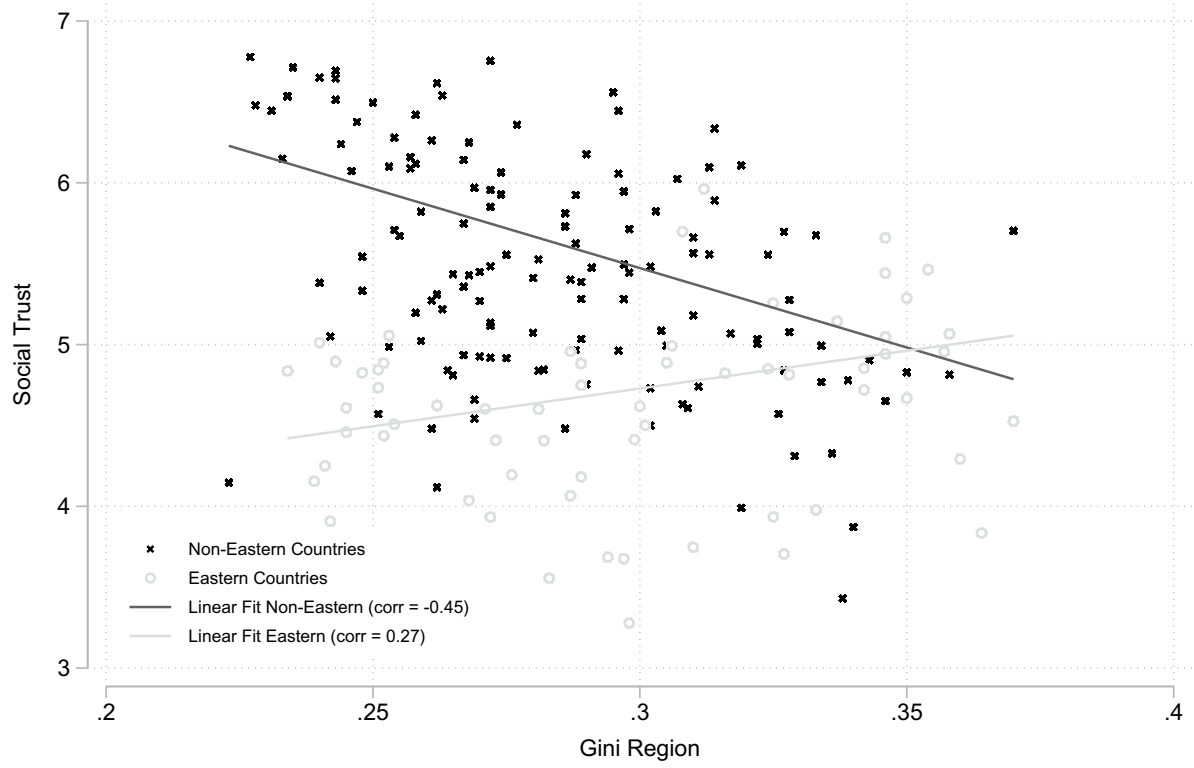

Fig. 4 Trust-inequality scatter. Regional Gini Coefficients retrieved from the Luxembourg Income Study and the OECD database of Regional Income Distribution and Poverty for the years reported in Table 1 . Regional Averages for Social Trust reported for 202 regions with more than 30 observations per region. Eastern Europe $=\mathrm{CZ}, \mathrm{EE}, \mathrm{HU}, \mathrm{LT}, \mathrm{PL}, \mathrm{SI}, \mathrm{SK}, \mathrm{RU}$

The results confirm Hypothesis 4, but provide only partial evidence for Hypothesis 3 as the negative inequality-trust linkage holds only across the non-Eastern countries. This squares with previous research arguing that the linkage is stronger if the Eastern European countries are excluded from the analysis (Uslaner, 2002). Online Appendix F shows that this negative moderation effect can only be partially reproduced by splitting the country sample according to GDP p.C., indicating that the differences across country groups cannot be entirely accounted for by different levels of economic development.

Finally, Models (3a) and (3b) disentangle the regional effects into within-country and between-country differences. In Model (3a), we find evidence that within-country differences in economic inequality are significantly associated to social trust, while betweencountry differences are not. Turning to economic development, the model provides positive evidence for within- and between-country effects. Affluent countries are more trusting than poor countries; and high-income regions are more trusting than low-income regions, controlling for country differences.

Moving to Model (3b), we recover the negative impact of Gini between as well as the within-country component. That is, in non-Eastern Europe between-country differences and within-country differences in inequality matter for social trust. In terms of magnitude, however, Gini between is more than three times larger than Gini within. This is visualized in the upper panel of Fig. 5, which illustrates the predicted values for social trust at different levels of Gini within and Gini between, holding the other variable and the control variables at the mean. The upper panel of Fig. 5 shows that the slope of Gini between is considerably steeper than the one of Gini within. Regarding the size of the effects, an increase of 0.25 in Gini within - that is a Gini coefficient 0.05 higher than the country average-decreases the trust score by 0.22 , whereas the same increase in Gini between leads to 
Table 2 Multilevel models: main results

\begin{tabular}{|c|c|c|c|c|}
\hline Variables & $\begin{array}{l}\text { (Model 1a) } \\
\text { Social trust }\end{array}$ & $\begin{array}{l}\text { (Model 1b) } \\
\text { Social trust }\end{array}$ & $\begin{array}{l}\text { (Model 2a) } \\
\text { Social trust }\end{array}$ & $\begin{array}{l}\text { (Model 2b) } \\
\text { Social trus }\end{array}$ \\
\hline Gini region & $\begin{array}{l}-0.51^{* *} \\
(0.20)\end{array}$ & $\begin{array}{l}-0.95^{* * *} \\
(0.23)\end{array}$ & & \\
\hline GDP p.C. region & $\begin{array}{l}2.02 * * * \\
(0.37)\end{array}$ & $\begin{array}{l}1.87 * * * \\
(0.40)\end{array}$ & & \\
\hline $\begin{array}{l}\text { Gini region } \times \text { Eastern } \\
\text { European }\end{array}$ & & $\begin{array}{l}1.41 * * * \\
(0.40)\end{array}$ & & \\
\hline $\begin{array}{l}\text { GDP p.C. region } \times \text { Eastern } \\
\text { European }\end{array}$ & & $\begin{array}{l}-2.27 \\
(1.20)\end{array}$ & & \\
\hline Gini country & & & $\begin{array}{l}-0.56 \\
(0.68)\end{array}$ & $\begin{array}{l}-2.71^{* *} \\
(0.88)\end{array}$ \\
\hline GDP p.C. country & & & $\begin{array}{l}2.58 * * * \\
(0.56)\end{array}$ & $\begin{array}{l}1.08 \\
(0.72)\end{array}$ \\
\hline $\begin{array}{l}\text { Gini country } \times \text { Eastern } \\
\text { European }\end{array}$ & & & & $\begin{array}{l}3.39 * * \\
(1.13)\end{array}$ \\
\hline $\begin{array}{l}\text { GDP p.C. country } \times \text { East- } \\
\text { ern European }\end{array}$ & & & & $\begin{array}{l}0.59 \\
(2.80)\end{array}$ \\
\hline
\end{tabular}

Gini between

Gini within

GDP between

GDP within

Gini between $\times$ Eastern

European

Gini within $\times$ Eastern

European

GDP between $\times$ Eastern

European

$\begin{array}{ll}-0.59 & -2.87 * * \\ (0.69) & (0.91) \\ -0.48 * & -0.87 * * * \\ (0.20) & (0.24) \\ 2.65 * * * & 1.20 \\ (0.57) & (0.74) \\ 1.61 * * * & 1.79 * * * \\ (0.46) & (0.47) \\ & 3.65 * *\end{array}$

GDP within $\times$ Eastern

European

Eastern European

$-0.55 *$

$-1.81 * *$

(0.28)

(0.63)

$-0.33$

(0.55)

Individual-level controls

Yes

Yes

Yes

Regional-level controls

Yes

Yes

Yes

Source control

Yes

Yes

Yes

Yes

Yes

Yes

Yes

Yes

Yes 
Table 2 (continued)

\begin{tabular}{lllllll}
\hline Variables & (Model 1a) & (Model 1b) & (Model 2a) & (Model 2b) & (Model 3a) & (Model 3b) \\
& Social trust & Social trust & Social trust & Social trust & Social trust & Social trust \\
\hline Var (Country) & 0.217 & 0.175 & 0.195 & 0.125 & 0.202 & 0.135 \\
Var (Region) & 0.077 & 0.069 & 0.084 & 0.085 & 0.075 & 0.068 \\
Var (Residual) & 2.806 & 2.806 & 2.806 & 2.806 & 2.806 & 2.806 \\
Observations & 38,951 & 38,951 & 38,951 & 38,951 & 38,951 & 38,951 \\
LL & $-69,156$ & $-69,148$ & $-69,163$ & $-69,159$ & $-69,155$ & $-69,145$ \\
chi2 & $2032 * * *$ & $2060 * * *$ & $2019 * * *$ & $2051 * * *$ & $2037 * *$ & $2079 * * *$ \\
AIC & $138,375.4$ & $138,365.4$ & $138,390.2$ & $138,387.6$ & $138,377.1$ & $138,368.2$ \\
BIC & $138,649.6$ & $138,665.4$ & $138,664.4$ & $138,687.6$ & $138,668.5$ & $138,702.4$ \\
\hline
\end{tabular}

Models from multilevel mixed-effects linear regression. Standard errors reported in parentheses. Gini and GDP p.C. are rescaled to [0,1]. Not reported: Constant. Individual-Level Controls: Income, Education, Gender, Age, Marital Status, Religiosity, Victim Crime, Household Size, Employment Status, Ethnic Minority, Foreign Born, Population Density, Share of Ethnic Minorities, Share of Foreign Born. Source Control: OECD Dummy. Post-stratification weights at the individual level and inverse probability weights at the country level

$* * * \mathrm{p}<0.001, * * \mathrm{p}<0.01, * \mathrm{p}<0.05$

a decrease of 0.72 in social trust. In a nutshell, although the analysis finds within-country differences in inequality to be meaningfully associated with social trust, the between-country difference is distinctly stronger (Hypothesis 5).

In the non-Eastern countries, GDP between turns insignificant, but the within-country difference in economic development still significantly relates to trust (Hypothesis 6). What is more, the within-country difference is also quantitatively more important than the (insignificant) between-country difference, as can be seen from the slopes of the two variables in the lower panel in Fig. 5. A 0.25 increase in GDP within leads to an increase in the trust score of 0.45 , whereas the same increase in GDP between implies a 0.3 (insignificantly) higher trust score. ${ }^{14}$

These results align with the intuition of the "size of the area"-claim and suggest that economic development is more important at lower levels of aggregation, whereas income inequality matters more in higher-level aggregates.

\section{Discussion and Conclusion}

Economic inequalities increasingly threaten the social fabric of European societies. In recent years, the academic community has robustly documented the influence of economic factors on trust, a central indicator for social cohesion. But at what level of aggregation do economic factors matter for social trust? This paper reexamines the trust-inequality nexus across 216 European regions in 22 countries and, in doing so, sheds light on its magnitude at different hierarchical levels.

\footnotetext{
${ }^{14}$ A possible concern relates to the number of countries at the third level, which falls slightly below the threshold mentioned in Bryan and Jenkins (2016). To address this concern, I reran the main models using bootstrapped standard errors in Online Appendix G. While as expected regional effects remain unchanged, the standard errors of the country-predictors increase. One should thus apply caution when interpreting the country-level estimates and discuss them against the backdrop of the evidence brought forth by previous cross-country studies (e.g., Barone and Mocetti, 2016).
} 

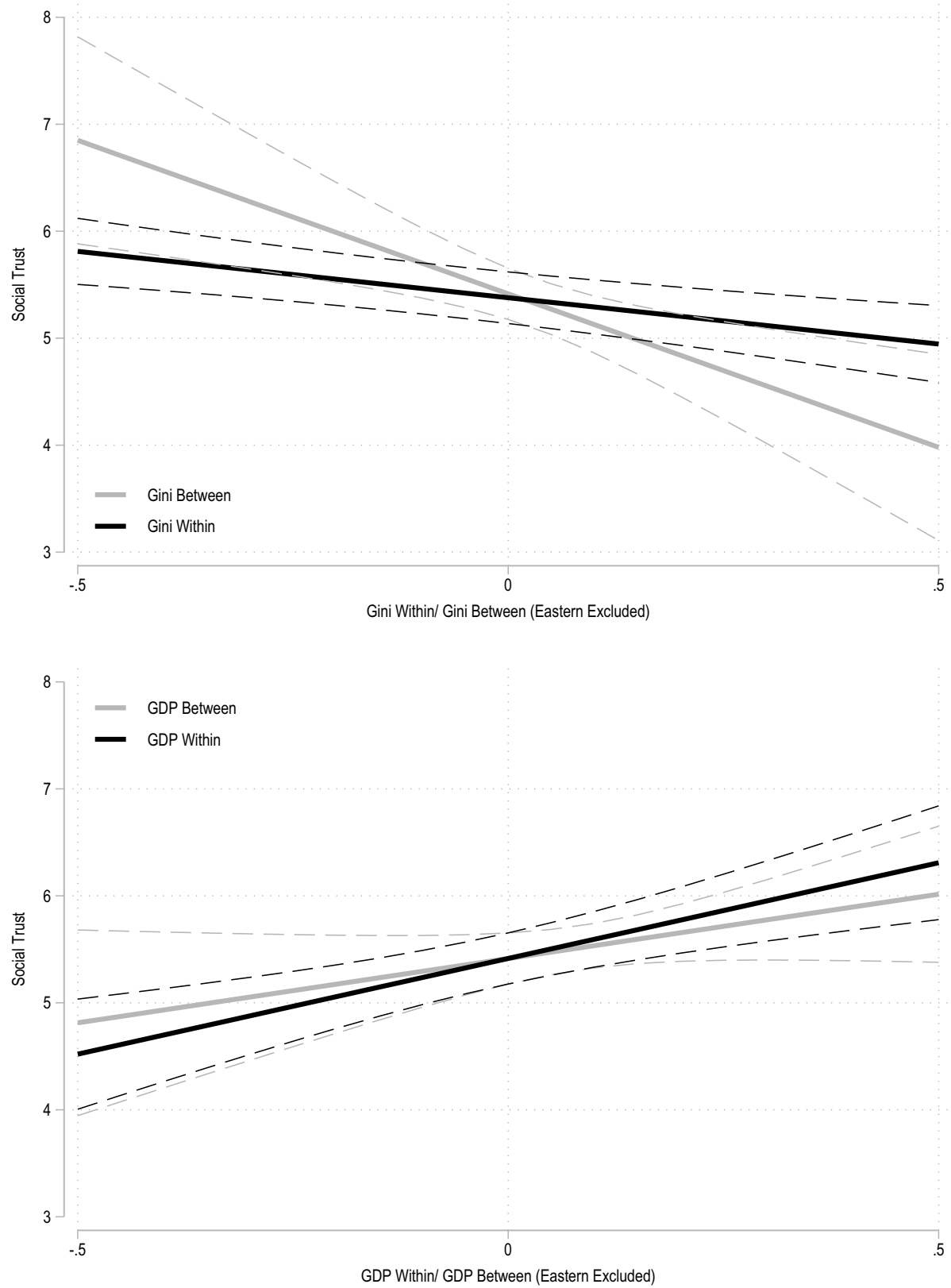

Fig. 5 Predicted values: multilevel model. Predicted values estimated from Model (3b) at mean of other variables. The $\mathrm{x}$-axis corresponds to the difference between the regional value and the country average for the rescaled Gini within- and GDP within-variables, or to the difference between a country value and the grand mean for the rescaled Gini between- and GDP between-variables. A 0.25 increase in the rescaled Gini (GDP p.C.) corresponds to a 0.05 (14.325) increase in Gini (GDP p.C.) 
The paper finds support for a negative association of income inequality and social trust across European regions. This finding chimes with recent evidence by Charron and Rothstein (2018), who likewise detect a negative association across European regions using another dataset and a different indicator for income inequality, the risk of poverty rate (see also, Ziller, 2015, whose analysis however does not reveal a negative association between this indicator and social trust). In analyzing this relationship at a different hierarchical level than most previous studies, my work adds to the empirical robustness of inequality-trust nexus.

Most importantly, however, the paper goes beyond prior work by disentangling the effect of income inequality on social trust into its between-country component and its within-country component. In doing so, the paper shows that, despite the sizeable impact of the withincountry component of regional inequality, most of the variation in social trust is accounted for by differences in inequality between countries. In other words, the effect of income inequality on the regional level can be attributed rather to differences between countries than to differences of the regions within countries. For economic development, we observe the opposite pattern. The within-country component of GDP per capita relates significantly to social trust, whereas differences in economic development between countries do not.

This phenomena is in line with the "size of the area"-claim by Wilkinson and Pickett (2009). The authors hypothesized that income inequalities matter most at upper contextual levels, whereas in small aggregates absolute income becomes a more decisive predictor. Past research has documented this pattern for health and psychological outcomes (Rostila et al., 2012), but the present analysis is the first to demonstrate this pattern for social trust across two hierarchical levels.

By doing so, the paper helps to synthesize conflicting evidence from studies zooming in on the inequality-trust nexus at different contextual levels. While international comparisons have overwhelmingly produced affirmative evidence at the country level (Barone \& Mocetti, 2016; Bjørnskov, 2008; Delhey \& Newton, 2005; Olivera, 2015; Rothstein \& Uslaner, 2005; Stephany, 2017), studies that have moved to smaller aggregates-like neighborhoods, counties, or districts-have failed to do so (Fairbrother \& Martin, 2013; Leigh, 2006a). In line, the present study demonstrates that the association between income inequality and social trust becomes weaker, as the analysis moves from countries to regions. Extrapolating from this finding, we would expect the relative importance of income inequality to decline even further in smaller aggregates. This conjecture, however, requires testing by comparative research at even lower levels of aggregation, which might also reveal effects of local inequality that were not captured by regional clusters.

This finding also holds implications for the established theoretical mechanisms underlying the inequality-trust nexus: social fractionalization and status competition. Although abundant research has tested these mechanisms in the context of income inequality (Delhey \& Dragolov, 2014; Hastings, 2018; Layte \& Whelan, 2014; Paskov, 2016; Paskov et al., 2017), it remains unclear to what level of aggregation they apply. The results suggest that social fractionalization and status competition might more strongly relate to the inequality of the income distribution as a whole rather than the inequality experienced in local contexts. While this is a step towards the theoretical refinement of these mechanisms, future research needs to assess their strength at different contextual levels directly by means of carefully designed survey questions.

Concluding that income inequality matters more on the national level naturally leads us to emphasize the merits of the welfare state and other societal institutions, which reduce social fractionalization and alleviate the socio-psychological ills from status competition. Eventually, also supranational institution such as the European Union might harm or foster social trust towards fellow citizens. Inasmuch as its policies shape inequality not just 
across, but also within countries, the European Union could also be a driving force of social cohesion in its member states.

The present paper has identified another limitation of the inequality-trust nexus. Thus, negative linkages at the regional and the country level only hold in a set of non-Eastern European countries (Uslaner, 2002, 2016). Previous studies have already pointed out that Eastern European countries are marked by low levels of social trust (Bjørnskov, 2007; Sarracino \& Mikucka, 2017) and that these can be mostly ascribed to weak economic development and a low quality of formal and informal institutions (Fidrmuc \& Gërxhani, 2008). On top of that, my analysis indicates that this country group also exhibits a categorically different inequality-trust pattern. To further explore this pattern, I follow recent insights that income inequality matters especially in wealthy countries (Barone \& Mocetti, 2016; Wilkinson \& Pickett, 2009). I find partial evidence that economic development conditions the inequality-trust association. This highlights the need for future investigations to examine the importance of democratic institutions not only for the absolute level of trust (Charron \& Rothstein, 2018), but also as a moderator of the inequality-trust nexus.

Importantly, the context of European regions naturally limits the availability of clusters at the third level (22 European countries). Thus, reservations with regard to the precision of the estimates at the macro (country) level and the accuracy of their standard errors may arise (Bryan \& Jenkins, 2016; Stegmueller, 2013). In this light, the country-level estimates should be interpreted with caution and against the background of the extant literature, which has so far convincingly demonstrated this relationship in cross-country analyses using broader sets of (developed) countries across the globe.

A natural progression to this work needs to incorporate the dimension of time to identify causal relationships between income inequality and social trust at different levels of aggregation. Indeed, a handful of recent studies has queried causal interpretations suggesting that the link holds in cross-sectional analyses exclusively, whereas changes in inequality are unrelated to changes in trust over time (Bergh \& Bjørnskov, 2014; Fairbrother \& Martin, 2013; Olivera, 2015). The robustness of this claim, however, seems to hinge strongly on the country sample. ${ }^{15}$ Whereas Fairbrother and Martin (2013) focus on US states and Olivera (2015) looks at European countries, Barone and Mocetti (2016) find evidence for a causal linkage in a broader set of developed countries (see also, Graafland \& Lous, 2019). Given the cross-sectional nature of the dataset, the analysis at hand does not permit us to conclude that the contextual variables affect social trust, instead of the other way around. Nevertheless, my work is informative to this discussion, since it addresses a related theoretical point asking to which level of aggregation the relationship and its potential mechanisms might apply.

If the debate is to be moved forward, research will also need to explore in how far the effect of income inequality on social trust might differ for socio-economic groups (Ravazzini \& Chávez-Juárez, 2018). Even though past work suggests that all income groups suffer from inequality (Layte \& Whelan, 2014), it might well be that the affluent are more prone to inequalities at the country level, whereas for the less well-off social comparisons within smaller units are more important.

\section{Appendix}

\footnotetext{
15 The claim also depends on the time-frame analysed, since both trust and income inequality are relatively stable over short periods.
} 
Table 3 Descriptive statistics

\begin{tabular}{|c|c|c|c|c|}
\hline Variables & Mean & SD & Range & Count \\
\hline \multicolumn{5}{|l|}{ Individual level } \\
\hline Trust (3 item scale) & 5.35 & 1.89 & $0-10$ & 38.951 \\
\hline Trust (1 item scale) & 5.18 & 2.38 & $0-10$ & 38.951 \\
\hline \multicolumn{5}{|l|}{ Subjective income } \\
\hline Living comfortably on & 0.31 & & $0 / 1$ & 38.951 \\
\hline Coping on & 0.46 & & $0 / 1$ & 38.951 \\
\hline Difficult on & 0.17 & & $0 / 1$ & 38.951 \\
\hline Very difficult on & 0.06 & & $0 / 1$ & 38.951 \\
\hline \multicolumn{5}{|l|}{ Education } \\
\hline ISCED 1 & 0.08 & & $0 / 1$ & 38.951 \\
\hline ISCED 2 & 0.17 & & $0 / 1$ & 38.951 \\
\hline ISCED 3 & 0.37 & & $0 / 1$ & 38.951 \\
\hline ISCED 4 & 0.06 & & $0 / 1$ & 38.951 \\
\hline ISCED 5-6 & 0.32 & & $0 / 1$ & 38.951 \\
\hline \multicolumn{5}{|l|}{ Gender } \\
\hline Male & 0.466 & & $0 / 1$ & 38.951 \\
\hline Female & 0.534 & & $0 / 1$ & 38.951 \\
\hline \multicolumn{5}{|l|}{ Marital status } \\
\hline Married & 0.51 & & $0 / 1$ & 38.951 \\
\hline Separated or divorced & 0.11 & & $0 / 1$ & 38.951 \\
\hline Widowed & 0.09 & & $0 / 1$ & 38.951 \\
\hline Never married & 0.29 & & $0 / 1$ & 38.951 \\
\hline \multicolumn{5}{|l|}{ Employment status } \\
\hline Paid work & 0.51 & & $0 / 1$ & 38.951 \\
\hline Unemployed & 0.06 & & $0 / 1$ & 38.951 \\
\hline Retired & 0.26 & & $0 / 1$ & 38.951 \\
\hline Other & 0.18 & & $0 / 1$ & 38.951 \\
\hline \multicolumn{5}{|l|}{ Household size } \\
\hline 1 & 0.21 & & $0 / 1$ & 38.951 \\
\hline 2 & 0.35 & & $0 / 1$ & 38.951 \\
\hline $3-5$ & 0.41 & & $0 / 1$ & 38.951 \\
\hline More than 5 & 0.03 & & $0 / 1$ & 38.951 \\
\hline Age & 49.19 & 18.39 & $15-102$ & 38.951 \\
\hline Religiosity & 4.37 & 3.06 & $0-10$ & 38.951 \\
\hline Foreign born & 0.09 & & $0 / 1$ & 38.951 \\
\hline Victim crime & 0.16 & & $0 / 1$ & 38.951 \\
\hline Ethnic minority & 0.06 & & $0 / 1$ & 38.951 \\
\hline \multicolumn{5}{|l|}{ Regional level } \\
\hline Gini & 28.85 & 3.64 & $0.22-0.42$ & 216 \\
\hline$G D P$ p.C & $24,400.65$ & $10,150.7$ & $9615-66,915$ & 216 \\
\hline Population density & 342.04 & 910.43 & $1-7260$ & 216 \\
\hline$\%$ Foreign born & 0.08 & 0.08 & $0-0.46$ & 216 \\
\hline$\%$ Ethnic minority & 0.05 & 0.07 & $0-0.48$ & 216 \\
\hline \multicolumn{5}{|l|}{ Country level } \\
\hline Gini & 29.32 & 3.33 & $0.24-0.35$ & 22 \\
\hline$G D P$ p.C & $25,629.74$ & $11,421.72$ & $11,297-61,802$ & 22 \\
\hline
\end{tabular}

Entries report unweighted and non-centred statistics 
Supplementary Information The online version contains supplementary material available at https://doi. org/10.1007/s11205-022-02894-w.

Acknowledgements The author sincerely thanks two anonymous reviewers for their valuable comments on earlier drafts of this manuscript.

Funding Open access funding provided by Vienna University of Economics and Business (WU). Not applicable.

Code Availability The Online Appendix and the code to replicate the data management and the analysis are available at: https://osf.io/wu69m/?view_only=9ee541a5110a4ee1aa5d4947bb059c72.

\section{Declarations}

Conflict of interest Not applicable.

Open Access This article is licensed under a Creative Commons Attribution 4.0 International License, which permits use, sharing, adaptation, distribution and reproduction in any medium or format, as long as you give appropriate credit to the original author(s) and the source, provide a link to the Creative Commons licence, and indicate if changes were made. The images or other third party material in this article are included in the article's Creative Commons licence, unless indicated otherwise in a credit line to the material. If material is not included in the article's Creative Commons licence and your intended use is not permitted by statutory regulation or exceeds the permitted use, you will need to obtain permission directly from the copyright holder. To view a copy of this licence, visit http://creativecommons.org/licenses/by/4.0/.

\section{References}

Alesina, A., \& La Ferrara, E. (2002). Who trusts others? Journal of Public Economics. https://doi.org/10. 1016/S0047-2727(01)00084-6

Allanson, P. (2014). Income stratification and between-group inequality. Economics Letters, 124(2), 227230. https://doi.org/10.1016/j.econlet.2014.05.025

Barone, G., \& Mocetti, S. (2016). Inequality and trust: New evidence from panel data. Economic Inquiry, 54(2), 794-809. https://doi.org/10.1111/ecin.12309

Bauer, P. C., \& Freitag, M. (2018). Measuring trust. In The Oxford handbook of social and political trust (pp. 15-36). Oxford University Press.

Bell, A., Jones, K., \& Fairbrother, M. (2018). Understanding and misunderstanding group mean centering: a commentary on Kelley et al.'s dangerous practice. Quality \& Quantity, 52(5), 2031-2036. https://doi. org/10.1007/s11135-017-0593-5

Bergh, A., \& Bjørnskov, C. (2014). Trust, welfare states and income equality: Sorting out the causality. European Journal of Political Economy, 35, 183-199. https://doi.org/10.1016/j.ejpoleco.2014.06.002

Beugelsdijk, S., de Groot, H. L. F., \& van Schaik, A. B. T. M. (2004). Trust and economic growth: A robustness analysis. Oxford Economic Papers, 56(1), 118-134. https://doi.org/10.1093/oep/56.1.118

Beugelsdijk, S., \& Van Schaik, T. (2005). Differences in social capital between 54 Western European regions. Regional Studies, 39(8), 1053-1064. https://doi.org/10.1080/00343400500328040

Bjørnskov, C. (2007). Determinants of generalized trust: A cross-country comparison. Public Choice, 130(1), 1-21. https://doi.org/10.1007/s11127-006-9069-1

Bjørnskov, C. (2008). Social trust and fractionalization: A possible reinterpretation. European Sociological Review, 24(3), 271-283. https://doi.org/10.1093/esr/jcn004

Bjørnskov, C., \& Svendsen, G. T. (2013). Does social trust determine the size of the welfare state? Evidence using historical identification. Public Choice, 157, 269-286. https://doi.org/10.1007/ s11127-012-9944-X

Bryan, M. L., \& Jenkins, S. P. (2016). Multilevel modelling of country effects: A cautionary tale. European Sociological Review, 32(1), 3-22. https://doi.org/10.1093/esr/jcv059

Charron, N., \& Rothstein, B. (2018). Regions of trust and distrust: How good institutions can foster social cohesion. In U. Bernitz, M. Martensson, L. Oxelheim, \& T. Persson (Eds.), Bridging the prosperity gap in the EU: The social challenge ahead (pp. 220-242). Elgar Online. https://doi.org/10.4337/97817 86436672.00017 
Cook, K. S. (2005). Networks, norms, and trust: The social psychology of social capital. Social Psychology Quarterly, 68(1), 4-14.

Delhey, J., \& Dragolov, G. (2014). Why inequality makes Europeans less happy: The role of distrust, status anxiety, and perceived conflict. European Sociological Review, 30(2), 151-165. https://doi.org/10. 1093/esr/jct033

Delhey, J., \& Newton, K. (2003). Who trusts?: The origins of social trust in seven societies. European Societies, 5(2), 93-137. https://doi.org/10.1080/1461669032000072256

Delhey, J., \& Newton, K. (2005). Predicting cross-national levels of social trust: Global pattern or nordic exceptionalism? European Sociological Review, 21(4), 311-327. https://doi.org/10.1093/esr/jci022

Delhey, J., Newton, K., \& Welzel, C. (2011). How general is trust in "most people"? Solving the radius of trust problem. American Sociological Review. https://doi.org/10.1177/0003122411420817

Dinesen, P. T. (2011). A note on the measurement of generalized trust of immigrants and natives. Social Indicators Research, 103(1), 169-177. https://doi.org/10.1007/s11205-010-9704-6

Durkheim, E. (1933). The divison of labor in society. The Free Press.

Enders, C. K., \& Tofighi, D. (2007). Centering predictor variables in cross-sectional multilevel models: A new look at an old issue. Psychological Methods. https://doi.org/10.1037/1082-989X.12.2.121

European Social Survey Cumulative File. ESS. (2020). Data file edition 1.0. NSD - Norwegian Centre for Research Data, Norway-Data Archive and distributor of ESS data for ESS ERIC.

Fairbrother, M., \& Martin, I. W. (2013). Does inequality erode social trust? Results from multilevel models of US states and counties. Social Science Research, 42(2), 347-360. https://doi.org/10.1016/j.ssres earch.2012.09.008

Fidrmuc, J., \& Gërxhani, K. (2008). Mind the gap! Social capital, East and West. Journal of Comparative Economics, 36(2), 264-286. https://doi.org/10.1016/j.jce.2008.03.002

Freitag, M., \& Traunmüller, R. (2009). Spheres of trust: An empirical analysis of the foundations of particularised and generalised trust. European Journal of Political Research, 48(6), 782-803. https://doi.org/ 10.1111/j.1475-6765.2009.00849.x

Gallego, A. (2016). Inequality and the erosion of trust among the Poor: Experimental evidence. Socio-Economic Review, 14(3), 443-460. https://doi.org/10.1093/ser/mww010

Giustozzi, C., \& Gangl, M. (2021). Unemployment and political trust across 24 Western democracies: Evidence on a welfare state paradox. Acta Sociologica, 64(3), 255-273. https://doi.org/10.1177/00016 993211008501

Glanville, J. L., Andersson, M. A., \& Paxton, P. (2013). Do social connections create trust? An examination using new longitudinal data. Social Forces, 92(2), 545-562. https://doi.org/10.1093/sf/sot079

Graafland, J., \& Lous, B. (2019). Income inequality, life satisfaction inequality and trust: A cross country panel analysis. Journal of Happiness Studies, 20(6), 1717-1737. https://doi.org/10.1007/ s10902-018-0021-0

Granovetter, M. (1985). Economic action and social structure: The problem of embeddedness. American Journal of Sociology, 91(3), 481-510.

Hardin, R. (1993). The street-level epistemology of trust. Politics \& Society, 21(4), 505-529. https://doi.org/ $10.1177 / 0032329293021004006$

Hastings, O. P. (2018). Less equal, less trusting? Longitudinal and cross-sectional effects of income inequality on trust in U.S. States, 1973-2012. Social Science Research, 74, 77-95. https://doi.org/10.1016/j. ssresearch.2018.04.005

Kawachi, I., Kennedy, B. P., Lochner, K., \& Prothrow-Stith, D. (1997). Social capital, income inequality, and mortality. American Journal of Public Health, 87(9), 1491-1498. https://doi.org/10.2105/ajph. 87.9.1491

Kevins, A. (2019). Dualized trust: Risk, social trust and the welfare state. Socio-Economic Review, 17(4), $875-897$.

Knack, S., \& Zak, P. J. (2003). Building trust: Public policy, interpersonal trust, and economic development. Supreme Court Economic Review, 10, 91-107.

Lambert, P. J., \& Aronson, J. R. (1993). Inequality decomposition analysis and the gini coefficient revisited. The Economic Journal, 103(420), 1221-1227. https://doi.org/10.2307/2234247

Larsen, C. A. (2013). The rise and fall of social cohesion: The construction and de-construction of social trust in the US. Oxford University Press. https://doi.org/10.1093/acprof:oso/9780199681846.003.0001

Layte, R., \& Whelan, C. T. (2014). Who feels inferior? A test of the status anxiety hypothesis of social inequalities in health. European Sociological Review, 30(4), 525-535. https://doi.org/10.1093/esr/jcu057

Leigh, A. (2006a). Trust, inequality and ethnic heterogeneity. Economic Record, 82(258), 268-280. https:// doi.org/10.1111/j.1475-4932.2006a.00339.x

Leigh, A. (2006b). Does equality lead to fraternity? Economics Letters, 93(1), 121-125. https://doi.org/10. 1016/j.econlet.2006.04.003 
Luxembourg Income Study. (2020). LIS database. http://www.lisdatacenter.org (multiple countries; microdata runs completed in Feb. 2020).

Neckerman, K. M., \& Torche, F. (2007). Inequality: Causes and consequences. Annual Review of Sociology, 33(1), 335-357. https://doi.org/10.1146/annurev.soc.33.040406.131755

OECD. (2016). Regional income distribution and poverty database. [Internet], [retrieved: 2020.12.17].

Olivera, J. (2015). Changes in inequality and generalized trust in Europe. Social Indicators Research, 124(1), 21-41. https://doi.org/10.1007/s11205-014-0777-5

Paldam, M., \& Svendsen, G. (2001). Missing social capital and the transition in Eastern Europe. Journal of Institutional Innovation, Development and Transition, 5, 21-34.

Paskov, M. (2016). Is solidarity less important and less functional in egalitarian contexts? Acta Sociologica, 59(1), 3-18.

Paskov, M., Gërxhani, K., \& van de Werfhorst, H. G. (2017). Giving up on the joneses? The relationship between income inequality and status-seeking. European Sociological Review, 33(1), 112-123. https:// doi.org/10.1093/esr/jcw052

Pichler, F., \& Wallace, C. (2007). Patterns of formal and informal social capital in Europe. European Sociological Review, 23(4), 423-435. https://doi.org/10.1093/esr/jcm013

Portes, A. (1998). Social capital: Its origins and applications in modern sociology. Annual Review of Sociology, 24(1), 1-24. https://doi.org/10.1146/annurev.soc.24.1.1

Ravazzini, L., \& Chávez-Juárez, F. (2018). Which inequality makes people dissatisfied with their lives? Evidence of the link between life satisfaction and inequalities. Social Indicators Research, 137(3), 1119-1143. https://doi.org/10.1007/s11205-017-1623-3

Reeskens, T., \& Hooghe, M. (2008). Cross-cultural measurement equivalence of generalized trust. Evidence from the European Social Survey (2002 and 2004). Social Indicators Research, 85(3), 515-532. https://doi.org/10.1007/s11205-007-9100-z

Robbins, B. G. (2016). What is trust? A multidisciplinary review, critique, and synthesis. Sociology Compass. https://doi.org/10.1111/soc4.12391

Rostila, M., Kölegård, M. L., \& Fritzell, J. (2012). Income inequality and self-rated health in Stockholm, Sweden: A test of the 'Income Inequality Hypothesis' on two levels of aggregation. Social Science \& Medicine, 74(7), 1091-1098. https://doi.org/10.1016/j.socscimed.2011.11.027

Rothstein, B., \& Uslaner, E. M. (2005). All for all: Equality, corruption, and social trust. World Politics, 58(1), 41-72. https://doi.org/10.1353/wp.2006.0022

Sarracino, F., \& Mikucka, M. (2017). Social capital in Europe from 1990 to 2012: Trends and convergence. Social Indicators Research, 131(1), 407-432. https://doi.org/10.1007/s11205-016-1255-Z

Savoia, F. (2019). Income inequality convergence across EU regions. LIS Working Paper Series, No.760, Luxembourg Income Study (LIS), Luxembourg.

Smith, S. S. (2010). Race and trust. Annual Review of Sociology, 36(1), 453-475. https://doi.org/10.1146/ annurev.soc.012809.102526

Snijders, T. A. B., \& Bosker, R. J. (2012). Multilevel analysis: An introduction to basic and advanced multilevel modeling. SAGE Publications.

Stegmueller, D. (2013). How many countries for multilevel modeling? A comparison of frequentist and Bayesian approaches. American Journal of Political Science, 57(3), 748-761. https://doi.org/10.1111/ ajps. 12001

Stephany, F. (2017). Who are your joneses? Socio-specific income inequality and trust. Social Indicators Research, 134(3), 877-898. https://doi.org/10.1007/s11205-016-1460-9

Subramanian, S. V., \& Kawachi, I. (2004). Income inequality and health: What have we learned so far? Epidemiologic Reviews, 26(1), 78-91. https://doi.org/10.1093/epirev/mxh003

Tabellini, G. (2010). Culture and institutions: Economic development in the regions of Europe. Journal of the European Economic Association, 8(4), 677-716.

Uslaner, E. M. (2002). The moral foundations of trust. Cambridge University Press. https://doi.org/10.2139/ ssrn. 824504

Uslaner, E. M. (2016). A reconsideration of Olivera's "Changes in inequality and generalized trust in Europe.” Social Indicators Research, 128(2), 723-729. https://doi.org/10.1007/s11205-015-1053-z

Uslaner, E. M., \& Brown, M. (2005). Inequality, trust, and civic engagement. American Politics Research, 33(6), 868-894. https://doi.org/10.1177/1532673X04271903

Van Lange, P. A. M. (2015). Generalized trust: Four lessons from genetics and culture. Current Directions in Psychological Science, 24(1), 71-76. https://doi.org/10.1177/0963721414552473

Welch, M. R., Sikkink, D., \& Loveland, M. T. (2007). The radius of trust: Religion, social embeddedness and trust in strangers. Social Forces, 86(1), 23-46.

Whiteley, P. F. (2000). Economic growth and social capital. Political Studies, 48(3), 443-466. https://doi. org/10.1111/1467-9248.00269 
Wilkinson, R. G., \& Pickett, K. E. (2006). Income inequality and population health: A review and explanation of the evidence. Social Science \& Medicine, 62(7), 1768-1784. https://doi.org/10.1016/j.socsc imed.2005.08.036

Wilkinson, R. G., \& Pickett, K. (2009). Income inequality and social dysfunction. Annual Review of Sociology, 35(1), 493-511. https://doi.org/10.1146/annurev-soc-070308-115926

Wilkinson, R. G., \& Pickett, K. E. (2017). The enemy between us: The psychological and social costs of inequality. European Journal of Social Psychology, 47(1), 11-24. https://doi.org/10.1002/ejsp.2275

Zak, P. J., \& Knack, S. (2001). Trust and growth. Economic Journal. https://doi.org/10.1111/1468-0297. 00609

Ziller, C. (2015). Ethnic diversity, economic and cultural contexts, and social trust: Cross-sectional and longitudinal evidence from European Regions, 2002-2010. Social Forces, 93(3), 1211-1240. https://doi. org/10.1093/sf/sou088

Publisher's Note Springer Nature remains neutral with regard to jurisdictional claims in published maps and institutional affiliations. 